\title{
Erratum
}

\section{Differential Effects of SKF 10,047 (N-Allyl-Normetazocine) on Peristalsis and Longitudinal Muscle Contractions of the Isolated Guinea-Pig Ileum}

\author{
W. Kromer ${ }^{1}$, N. Steigemann ${ }^{2}$, and G. T. Shearman ${ }^{2}$ \\ ${ }^{1}$ Abteilung Allgemeine Pharmakologie, Medizinische Hochschule Hannover, Karl-Wiechert-Allee 9, D-3000 Hannover 61, and \\ ${ }_{2}^{2}$ Max-Planck-Institut für Psychiatrie, Neuropharmakologische Abteilung, Kraepelinstrasse 2, D-8000 München 40, Federal Republic of Germany
}

The A, B, and C designations of Figure 2 were unfortunately omitted through a printing error. Therefore, Figure 2 is being reprinted as it should have appeared.
On page 219 , column 2 , line 2 , during the final printing process an unfortunate error was made. "D-Ser'-D Leusenkephalyl-Thr" should read "D-Ser'-L-Leu'-enkephalylThr".

A

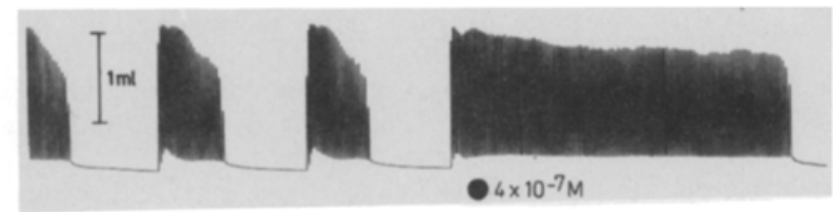

B

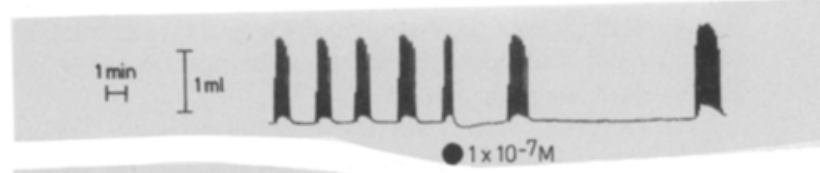

C

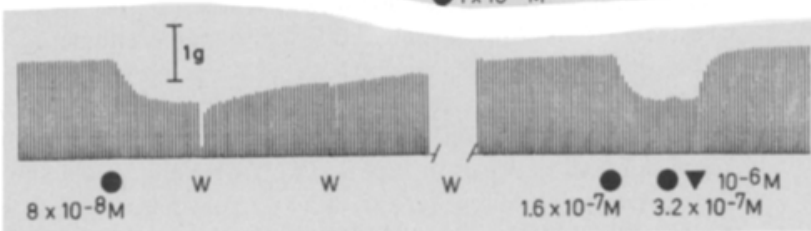

Fig. 2. Action of SKF 10,047 (๑) on spontaneous peristalsis (distension stimulus only, no addition of acetylcholine); $(\mathbf{A}, \mathbf{B})$ or electrically induced contractions of the myenteric plexus-longitudinal muscle-preparation of the guinea-pig ileum (C). (A) Enhancement of peristaltic activity by SKF $10,047\left(4 \times 10^{-7} \mathrm{M}\right)$. (B) Inhibition of peristaltic activity by SKF 10,047 $\left(1 \times 10^{-7} \mathrm{M}\right)$. This effect was obtained only in a few segments and was not statistically singificant (see Fig. 1) with regard to groups of segments. (C) Inhibition of electrically induced longitudinal muscle contractions by SKF 10,047. The example demonstrates the failure of SKF 10,047 to completely inhibit the longitudinal muscle contraction. The ceiling effect produced by SKF 10,047 (see also Fig. 1) suggests that full activation of $\sigma$-receptors by SKF 10,047 is insufficient for complete inhibition of twitch tension, which requires additional activation of other types of opioid receptors. The inhibition caused by SKF 10,047 was completely antagonized by naloxone at $10^{-6} \mathrm{M}(\mathbf{\nabla})$ 